\title{
Improvement of Local Soils in Order to Make "Fast \& Bouncy" Cricket Pitches
}

\author{
U P Nawagamuwa, A I M J Senanayake, S A Silva and D M I Sanjeewa
}

\begin{abstract}
The playing character of pitches varies considerably from country to country and generally, pitches in the Indian subcontinent are regarded to be 'slow, low \& dusty' in contrast to Australian or South African pitches which are 'fast \& bouncy'. Sri Lankan players find it particularly hard to adapt to fast and bouncy pitches because they seldom find comparable playing conditions at home. This project tried to address this problem by investigating the possibility of improving the soils used in local cricket pitches in order to make them produce 'fast \& bouncy' pitches.
\end{abstract}

Data was gathered from local pitches by collecting and analyzing soil samples from Test venues in the vicinity of Colombo. This data was then compared to available data from other countries, especially Australia (due to similar climatic conditions). It was found that local pitches had high silt content, low clay content and low plasticity due to a difference in clay mineralogy when compared to Australian pitches. It was hypothesized that by reducing the silt content and improving the plasticity by the introduction of Bentonite (a clay type with very high plasticity) in to the soil would produce a faster and bouncier pitch of similar character to those in Australia. Small scale model pitches were built and then tested to find the effect the additional Bentonite on the pitch characteristics.

Keywords: cricket pitches, soil grading, clay mineralogy, pace, bounce

\section{Introduction}

Cricket is easily the most popular sport in Sri Lanka. It has won the hearts and minds of the people of this country so much that it has turned in to a national pastime. It is a very complicated game with many facets to it which often leaves the layman confounded by its complexity.

In Cricket, the conditions in which the game is played is very important. Weather, playing surface, ground conditions and many other variables play a part. Especially important among these is the playing surface also called the "Cricket Pitch". Unlike many other sports, the playing area is not artificial and as a result the playing conditions in each game are unique. Cricket pitches have over the years been categorized according to their behaviour. Players have learnt to adapt to how the pitches behave in order to perform better. Of these categories of pitches, the most common are the "fast" and "slow" pitches. "Fast" pitches quite commonly are "bouncy" pitches as well while "slow" pitches tend to be "low", dusty and conducive to "spin".

Sri Lanka (as well as most of the Indian Subcontinent) is home to "slow and low" pitches and even though it has been attempted, the creation of fast, bouncy pitches in Sri Lanka has eluded us. This paper deals with the problem of creating a fast and bouncy pitch by investigating how some of the fundamental physical characteristics of a cricket pitch varies with the soil used to make the pitch

\section{Playing character of cricket pitches}

The following terms are used in cricket in order to describe the behaviour of pitches.

- Pace

- Bounce

- Spin

- Consistency

- Deterioration

'Pace' describes as to how fast a delivery will come at the batsmen after bouncing. It basically depends on the horizontal velocity component of the ball and higher the horizontal velocity

\footnotetext{
Eng. (Dr.) U.P. Nawagainuwa B.Sc. Eng. (Hons), MEng (AIT), Dr.Eng (YNU), C.Eng, MIE (Sri Lanka) is a Senior Lecturer in the Department of Civil Engineering, University of Moratwua. His research interests are in the fields of Geotechnical and Geo-Environmental Engineering. A.I.M.J Senanayake B.Sc. Eng. (Hons) (Moratuwa) S.A. Silva B.Sc. Eng. (Hons) (Moratuwa) D.M.I Sanjecwa B.Sc. Eng. (Hons) (Moratuwa) Are recent graluates with diverse research interests in the ficlds of Geotechnical Engineering. Structural Engineering and Spurts Engineering
} 
retained after bouncing greater will be the pace of the pitch.

'Bounce' describes the steepness of the path of a delivery after bouncing. The main factor which governs 'bounce' is the vertical velocity gained by the ball after its impact with the pitch.

'Spin' describes the affinity of a delivery to undergo lateral movement after bouncing due to the rotational motion of the ball. The friction between the ball and the pitch is the governing factor for 'spin' with high coefficients of friction likely to produce greater lateral movement.

'Consistency' is perhaps the most important of all pitch characteristics. It describes the variation of each of the above factors in a pitch. If the pitch characteristics change greatly from one area to another on the same pitch, the surface becomes unsuitable for play. The nature of a match depends very much on the 'consistency' of a pitch as a high level of 'consistency' means a batsmen is better able to predict the path of a delivery and thus will find batting easier. Likewise, a lower level of 'consistency' will help bowlers and make batting harder. Highly inconsistent pace and spin will make batting almost impossible while inconsistent bounce will be dangerous to the batsmen. Thus, a certain minimum level of 'consistency' is mandatory for a proper game of cricket to be played.

'Deterioration' describes the length of time a pitch is likely to maintain a certain level of 'pace' and 'bounce'. All pitches lose 'pace' and 'bounce' with time due to wear and tear of the surface.

According to experts, Sri Lankan pitches differ from Australian, South African and English

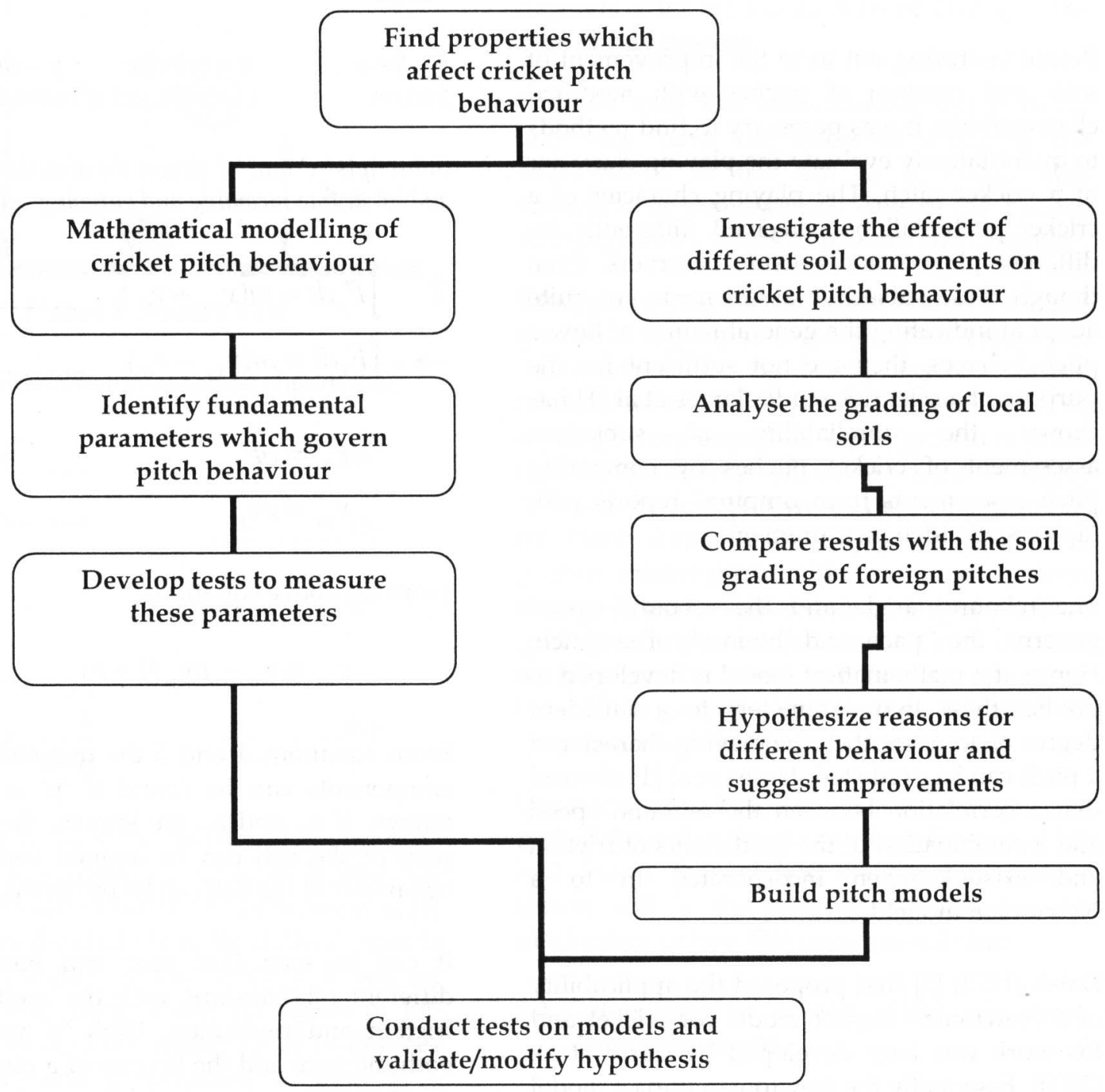

Figure 1: Schematic representation of methodology adopted 
pitches in three of the above characteristics. They are namely, 'pace', 'bounce' and 'deterioration'. Sri Lankan pitches as well those in the Indian sub-continent in general have lower 'pace' and 'bounce' and also deteriorate much faster.

\section{Methodology}

The methodology adopted was to compare the soil makeup of Sri Lankan pitches to those of Australian pitches, identify the major differences, modify the local soil so that these differences were minimized and conduct tests to check how successful the modified soil was at producing faster and bouncier pitches.

The whole process represented as a schematic diagram in figure 1.

\subsection{Predicting the playing character of pitches through mathematical modelling}

Before venturing out in to the improvement of soils and creation of pitches with modified characteristics it was necessary to find methods to quantitatively evaluate the playing character of a cricket pitch. The playing character of a cricket pitch will be perceived differently by different players and outside observers. Even though these subjective assessments are quite adept at indicating the general nature of how a pitch behaves, they are not sufficient for the purpose of a scientific study. James et al [1] has shown the unreliability of subjective assessment of cricket pitches by comparing pitch assessments from umpires' reports with high speed video measurements.

The rebound angle and the rebound speed governs the 'pace and bounce' of a pitch. Hence, if a mathematical model is developed to predict these two parameters to a sufficient degree of accuracy then the playing character of a pitch can be predicted. James et al [1] showed that a correlation between the rebound speed and a combination of the coefficients of friction and existed when incorporated in to a Newtonian model.

Daish (1972) [2] first proposed the applicability of a Newtonian impact model for cricket and his work was later developed by Carre et al. (2000). Essentially the Newtonian impact model allows for no deformation of either the surface or the ball and calculates the ball rebound dynamics using a combination of friction and restitution measurements [1].

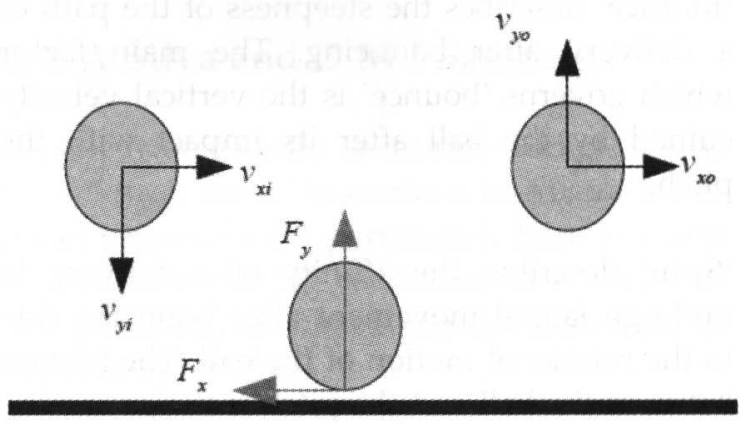

Figure 2: Impact between ball and surface

The governing equations for this model are as follows:

(Even though the rotation and the angular momentum have been included in the original model it is neglected to further simplify the model for this study.)

F-force

friction

$$
\begin{gathered}
v \text {-velocity } \quad \mu \text {-coefficient of } \\
e \text {-coefficient of restitution }
\end{gathered}
$$

Subscripts ' $x$ ' and ' $y$ ' denote the direction while ' $i$ ' and ' $\mathrm{o}$ ' denote incoming and outgoing velocities.

$$
\begin{aligned}
\uparrow \quad \int F_{y} d t & =m\left(v_{y o}+v_{y i}\right) \\
\rightarrow-\int F_{x} d t & =m\left(v_{x o}-v_{x i}\right) \\
F_{x} & =\mu F_{y} \\
v_{y o} & =e v_{y i}
\end{aligned}
$$

From the above equations,

$$
v_{x o}=v_{x i}-\mu v_{y i}(1+e)
$$

From equations 4 and 5 the outgoing velocity components can be found if ' $\mu$ ' and ' $\mathrm{e}$ ' are known. If $v_{x o}$ and $v_{y_{0}}$ are known, the complete path of the ball can be defined and thus the behaviour of the ball can be predicted.

It can be seen that pace and bounce have different relationships with the coefficients of friction and restitution. High ' $\mathrm{e}$ ' values help both the pace and the bounce of a pitch but the effect of ' $\mu$ ' is not as straightforward. Lower ' $\mu$ ' values will make a cricket pitch faster while higher ' $\mu$ ' values will make the pitch bouncier. 
This higher bounce is due to the decreasing of the horizontal velocity component which makes the gradient of the path of the rebounding ball steeper. High bounce based on high ' $\mu$ ' values is not recommended for cricket pitches as it causes high loss of pace making the pitch nonconducive for stroke-play.

\subsection{Tests to measure ' $\mathrm{e}$ ' and ' $\mu$ ' of pitches}

\section{Bounce Test}

In order to find the coefficient of restitution of a surface, a cricket ball is dropped from a certain height ' $\mathrm{H}$ ' and the rebound height ' $\mathrm{h}$ ' is measured.

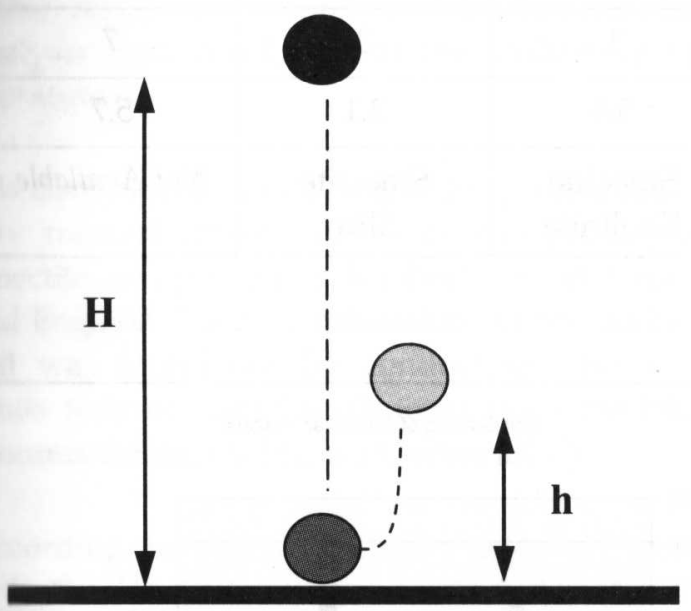

Figure 3: Bounce Test

From simple mechanics it can be shown that,

$v_{i}=\sqrt{2 g H}$

$v_{o}=\sqrt{2 g h}$

$e=\frac{v_{o}}{v_{i}}$

Therefore, $e=\sqrt{\frac{h}{H}}$

In order to simulate an impact of comparable magnitude to a delivery from a fast bowler, the drop height was chosen to be $4 \mathrm{~m}$. James et al [3] had conducted a study in to the delivery speeds and impact angles of fast bowlers. Based on data from that study, a delivery speed of 130 $\mathrm{kmh}^{-1}$ and an angle of incidence of 14 degrees were chosen and it simulated a 'short of a length' delivery from a fast bowler.

\section{Friction Test}

The coefficient of friction is found out by measuring the frictional force acting on a sled when it is been dragged across a cricket pitch. The surface of the sled in contact with the pitch should be similar to that of a cricket ball. James et al [1] had used a friction sled made by clamping three cricket balls between two triangular metal plates in such a way that the balls protruded through holes in the plates.

\subsection{Effect of different soil components on cricket pitch behaviour}

Cricket pitches are hard blocks of earth consisting of aggregates of varying sizes held together very firmly by a strong binding agent. The aggregate mix consists of coarse sand, fine sand, silt and clay. The clay acts as the binding agent and holds all the aggregate together. The strength and durability of a cricket pitch thus depends a lot on the amount of clay and the type of clay present.

Silts are very fine non-cohesive soil particles and they have the effect of reducing the cohesiveness of the soil as a whole. This reduction in cohesiveness causes the pitches with high silt contents to powder and crumble.

Sand grains play an important role in the plant growth in a pitch by helping initiate cracks but too much coarse sand will increase surface friction and cause ball damage. The cracking of a pitch is very important to the growth of grass as without cracks it will be very hard for water to reach the root systems of the plants through the highly impermeable clayey soil [8] used to prepare cricket pitches. The grass root systems improve the stability and durability of a cricket pitch by acting as reinforcement. Grass also has an effect on the 'pace' and 'bounce' of a pitch but for the purpose of this study the effect of grass as a whole has been neglected.

Organic content in the soil is also an important part of the soil makeup of a pitch. Carre et al [4] had found that higher the organic content slower will be the pace of the pitch but the mechanism of how this occurs is not clear.

\subsection{Comparison of cricket pitch soils from around the world}

Data on the soil grading and soil mineralogy of cricket pitch soils from Australia, England and Sri Lanka were obtained and analysed in order 
to find out how they differed from one another. Surprisingly, it was found out that English pitches and Sri Lankan pitches are quite similar in their soil grading and mineralogy. The difference in behaviour was therefore attributed to the very different climatic conditions prevailing in the two countries.

Australian and Sri Lanka have similar climates but the soil grading and mineralogy of pitches from the two countries was found be very different.

Table 1: Soil components of Australian pitches

\begin{tabular}{|l|c|c|c|c|c|}
\hline Soil & Adelaide & Brisbane & MCG & Perth & SCG \\
\hline Clay & 51 & 68 & 53 & 82 & 52 \\
\hline Silt & 14 & 6 & 21 & 6 & 22 \\
\hline Fine Sand & 25 & 5 & 20 & 6 & 15 \\
\hline Coarse Sand & 7 & 1 & 1 & 2 & 7 \\
\hline Organic Matter & 2.2 & 5.5 & 5.4 & 2.1 & Not Available \\
\hline Type of Clay & $\begin{array}{c}\text { Smectite } \\
\text { Illite }\end{array}$ & $\begin{array}{c}\text { Smectite } \\
\text { Illite }\end{array}$ & $\begin{array}{c}\text { Smectite } \\
\text { Kaolinite }\end{array}$ & $\begin{array}{c}\text { Smectite } \\
\text { Illite }\end{array}$ \\
\hline
\end{tabular}

(NZSTI Guide to Cricket Pitch Preparation)
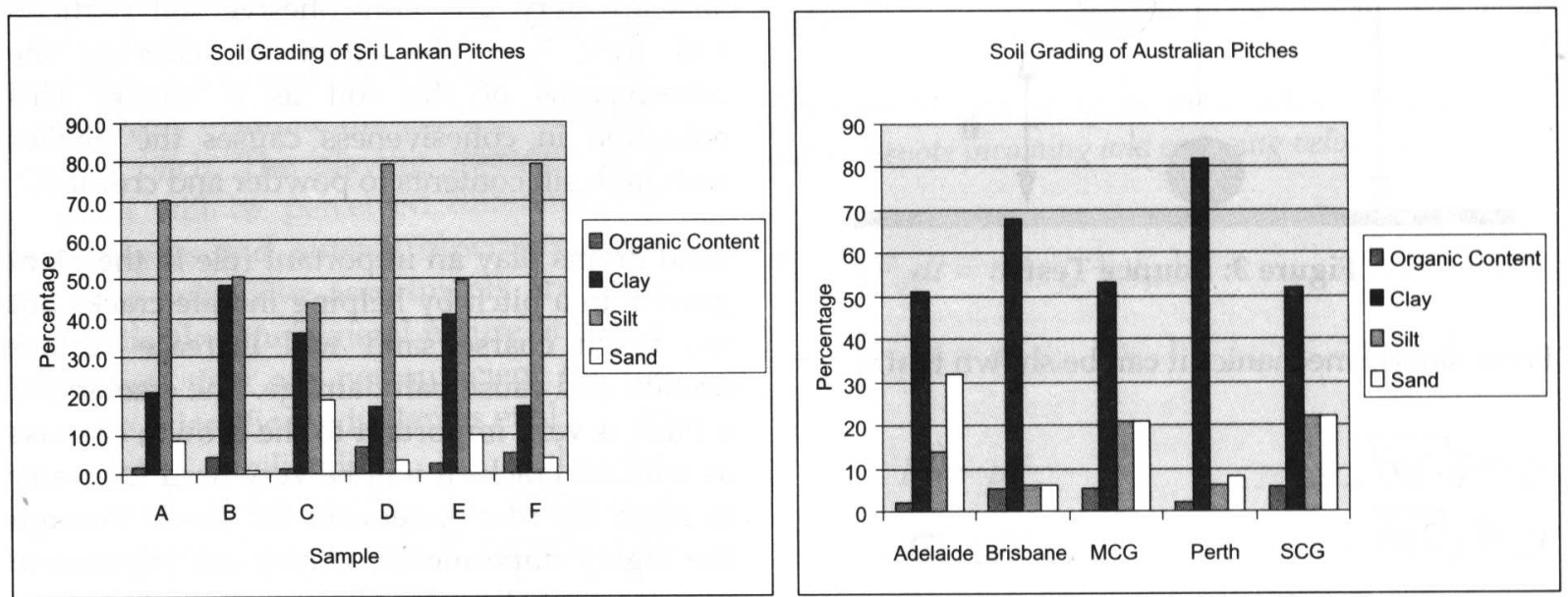

Figure 4: Soil Grading of Sri Lankan and Australian Pitches
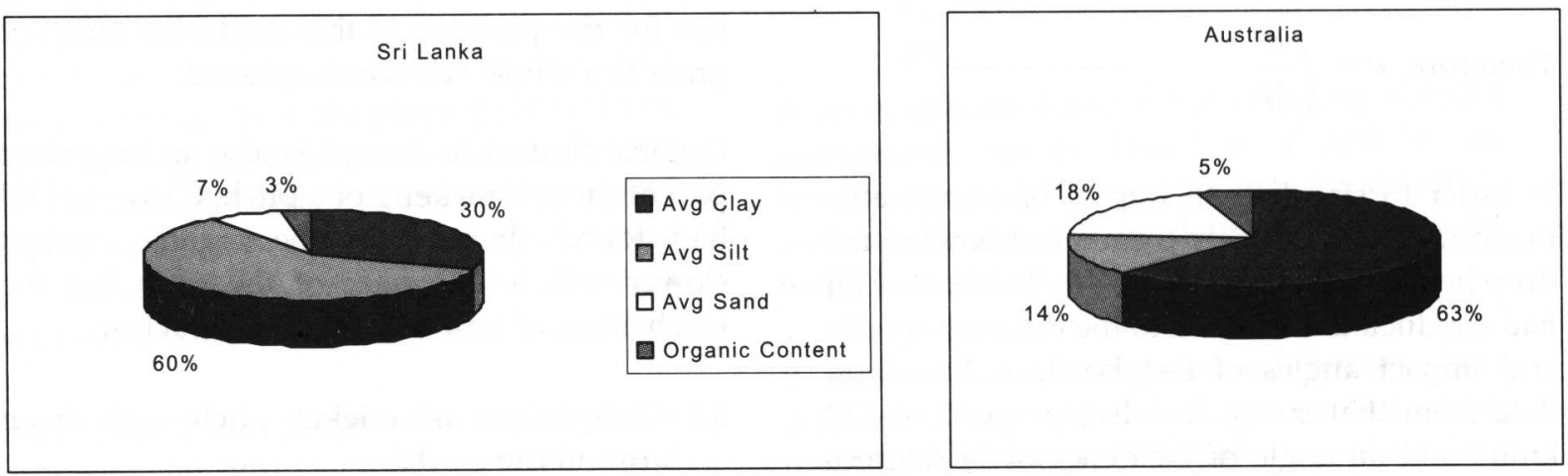

Figure 5: Average grading of cricket pitch soils in Sri Lanka and Australia

(Data courtesy of Sri Lanka Cricket and NZSTI[5]) 
The following important points should be noted from the above charts:

- The predominant soil component in Australian pitches is clay while in Sri Lankan pitches it is silt.

- The clay content in Australian pitches is in the range of $50 \%-80 \%$ while in Sri Lankan pitches it is in the range of $20 \%$ to $45 \%$

- The silt content in Australian pitches is in the range of $5 \%-20 \%$ while in Sri Lanka pitches it is in the range of $45 \%-80 \%$

The soil grading data was obtained from the tests conducted by the Industrial Technology Institute (ITI) using laser particle analysing. These results were confirmed by hydrometer analysis tests conducted at the University of Moratuwa.

It is also important to note that the predominant clay mineral present in Australian pitches is Smectite as opposed to Kaolinite in Sri Lanka and England. The clay mineralogy of Sri Lankan soil was found out by conducting Atterberg limits tests on samples obtained from the SSC grounds through Sri Lanka Cricket (SLC).

According to Atterberg limits tests on local soils, the 'Plasticity Index' was 14 and 'Activity' was 0.42 which implied that the predominant clay mineral was kaolinite..

In order understand the significance of the difference in clay mineralogy between the local and Australian soils it is necessary to look at some of the properties of the two clay types.

Table 2: Differences between Kaolinite and Smectite

\begin{tabular}{|l|l|}
\hline \multicolumn{1}{|c|}{ Kaolinite } & \multicolumn{1}{c|}{ Smectite } \\
\hline Low plasticity & Very high plasticity \\
\hline $\begin{array}{l}\text { Low drying } \\
\text { shrinkage }\end{array}$ & $\begin{array}{l}\text { High drying } \\
\text { shrinkage }\end{array}$ \\
\hline Less cracking & More cracking \\
\hline $\begin{array}{l}\text { Low compressive } \\
\text { strength }\end{array}$ & $\begin{array}{l}\text { High compressive } \\
\text { strength }\end{array}$ \\
\hline
\end{tabular}

(Herath [6])

Higher plasticity and higher compressive strength of smectite seems like a very probable explanation for the harder, bouncier and more resilient pitches in Australia. Pitches in Perth and Brisbane are considered to be the fastest and bounciest pitches in Australia [5] and it is no coincidence that they happen to have the highest clay contents and that their clay mineralogy is predominantly smectite. The pitches at the MCG in Melbourne tend to breakup prematurely [5] and the fact that significant levels of kaolinite are present in that soil highlights the effect of kaolinite on pitches.

The only concern in using soils with high levels of smectite is that extensive cracking is likely to occur due to the high drying shrinkage. However, the authors are confident that even though cracking will be extensive the pitch will not crumble. This reasoning is based on the behaviour of the pitch at the WACA in Perth which shows extensive cracking [5] most likely due to its clay mineralogy being predominantly smectite but it is still a very 'true' and consistent pitch probably because the higher strength of the clay keeps the pitch from crumbling.

\section{4. 'Weaknesses' in local soil}

From the above data, weaknesses in local soils when compared Australian soils are clearly apparent. These weaknesses may be summarised as follows:

- Clay content is too low

- Silt content is too high

- Plasticity of the clay present is low

All three of the above factors contribute to the creation of pitches which are likely to deteriorate quickly due to the lack of cohesiveness and plasticity and also produces surfaces which are lower in strength.

\subsection{Improvements}

Now that the possible reasons for the nature of local pitches had been hypothesized, the next step was to test this hypothesis which implied that if the plasticity of the soil is improved and the silt content is reduced, the soil ought to produce a pitch with good 'pace', 'bounce' and high resistance to deterioration. So, bentonite which is a commercially available form of smectite was added to the local soil and then tests were carried out in order find out if any improvements were shown. The targeted clay content was $50 \%$. 
Bentonite was added after crushing the available soil in to fine particles and mixed using a concrete mixer. The original soil had to be crushed in order to ensure that a uniform and homogeneous mix was obtained as the soil was in the form of clay granules.

The particle size distributions of the original soil samples and that of the modified soil sample are show above. As can be seen the clay content of the modified sample has increased up to $45 \%$ while the silt content has decrease from about $65 \%$ to about $45 \%$.

This soil grading suggested that the mixing of bentonite with the original soil had been successful.

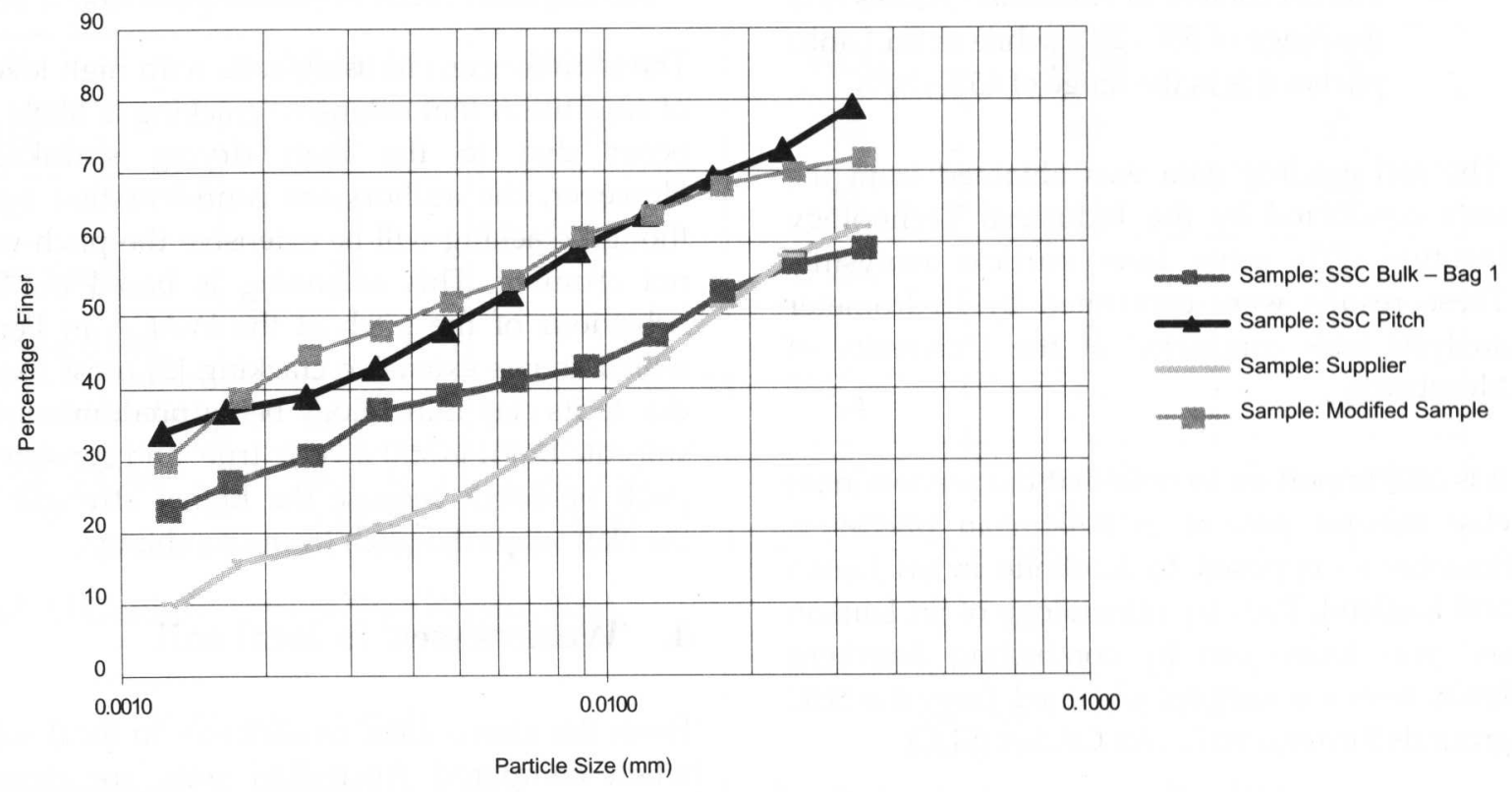

Figure 6: Particle size analyses of soil samples from the supplier and of the modified soil

\section{Plasticity}

Liquid limit $\quad=64 \%$

Plastic limit $=42 \%$

Plasticity Index $=22$

Table 3: Improvements in the modified soil

\begin{tabular}{|c|c|c|}
\hline & $\begin{array}{c}\text { Original } \\
\text { Soil }\end{array}$ & $\begin{array}{c}\text { Modified } \\
\text { Soil }\end{array}$ \\
\hline $\begin{array}{c}\text { Clay } \\
\text { content }\end{array}$ & $25 \%$ & $45 \%$ \\
\hline Silt content & $65 \%$ & $45 \%$ \\
\hline Plasticity & 14 & 22 \\
\hline
\end{tabular}

\subsection{Model Testing}

Since the tests on the modified soil showed encouraging results, the next step was to test the actual playing character of a pitch produced by that soil against that of a pitch produced by the original soil. For this, two pitch models were constructed; the first was a control model constructed using the original soil from the SSC grounds while the second was the test model constructed using the modified soil.

The models were constructed in boxes of approximately $30 \mathrm{~cm} \times 25 \mathrm{~cm} \times 25 \mathrm{~cm}$ in size. The soil layer was made to be $10 \mathrm{~cm}$ deep with a base layer of $20 \mathrm{~mm}$ metal $15 \mathrm{~cm}$ deep provided as founding material. Cores were extracted from the SSC and NCC pitches to find the insitu density and the degree of compaction to which those pitches had been subjected to and those conditions were recreated in the models. It was found out that the pitches had undergone a degree of compaction of $100 \%-105 \%$ when compared with the results from a standard Proctor compaction test. 
the clay ncreased decrease

nixing of ad been

Bulk - Bag 1 itch

showed $\mathrm{s}$ to test roduced luced by models ol model the SSC it model

oxes of size. The with a rovided xtracted he insitu o which an those s. It was rgone a $\%$ when tandard
In the construction of the models, a degree of compaction of $100 \%$ was used and the compacting was done in 3 layers using a standard Proctor compaction hammer. Once the compaction was completed, the top surface was amoothened and levelled and the model was left in the sun to dry. Once the model was dry enough and hard enough the following tests were carried out to determine the playing character of the model pitches.

1. Bounce test

2. Friction test

3. Penetration test using a Proctor Penetrometer

4. Crack pattern observation and crack width measurement

5. Moisture content measurement

Three sets of data were recorded at three different moisture contents for each model and the results are as follows:

\section{Bounce Test}

The test results were disappointing at first since the expected increase in bounce was not observed. From Table 3 it can be seen that the control model actually shows more bounce than the modified model but when the ' $\mathrm{e}$ ' vales obtained were plotted against the moisture content at which they were measured, an encouraging pattern emerged. The plot of ' $\mathrm{e}$ ' vs moisture content shows that the ' $\mathrm{e}^{\prime}$ value of the modified model increases at a steeper gradient with the reduction in moisture than the control model. It also shows that the ' $\mathrm{e}$ ' value of the modified model surpasses the ' $\mathrm{e}$ ' value of the modified model below a moisture content of about $8 \%$.

Table 4: Bounce Test Results

\begin{tabular}{|c|c|l|l|c|}
\hline & $\begin{array}{c}\text { Moistur } \\
\mathrm{e}\end{array}$ & $\begin{array}{l}\mathbf{H} \\
\mathbf{( c m})\end{array}$ & $\begin{array}{l}\mathbf{h} \\
\mathbf{( c m})\end{array}$ & $\mathbf{e}^{\prime}$ \\
\hline \multirow{3}{*}{$\begin{array}{c}\text { Control } \\
\text { Model }\end{array}$} & $7.5 \%$ & 400 & 130 & 0.570 \\
\cline { 2 - 5 } & $13 \%$ & 400 & 126 & 0.561 \\
\cline { 2 - 5 } & $22 \%$ & 400 & 118 & 0.543 \\
\hline \multirow{3}{*}{$\begin{array}{c}\text { Modified } \\
\text { Model }\end{array}$} & $10 \%$ & 400 & 126 & 0.561 \\
\cline { 2 - 5 } & $14 \%$ & 400 & 118 & 0.543 \\
\cline { 2 - 5 } & $19 \%$ & 400 & 107 & 0.517 \\
\hline
\end{tabular}

Even though the trend lines have been extended backwards to down to $0 \%$ moisture, it is only to highlight the trend in the data variation as in reality, the minimum moisture content in a pitch was found to hover between $6 \%-8 \%$.

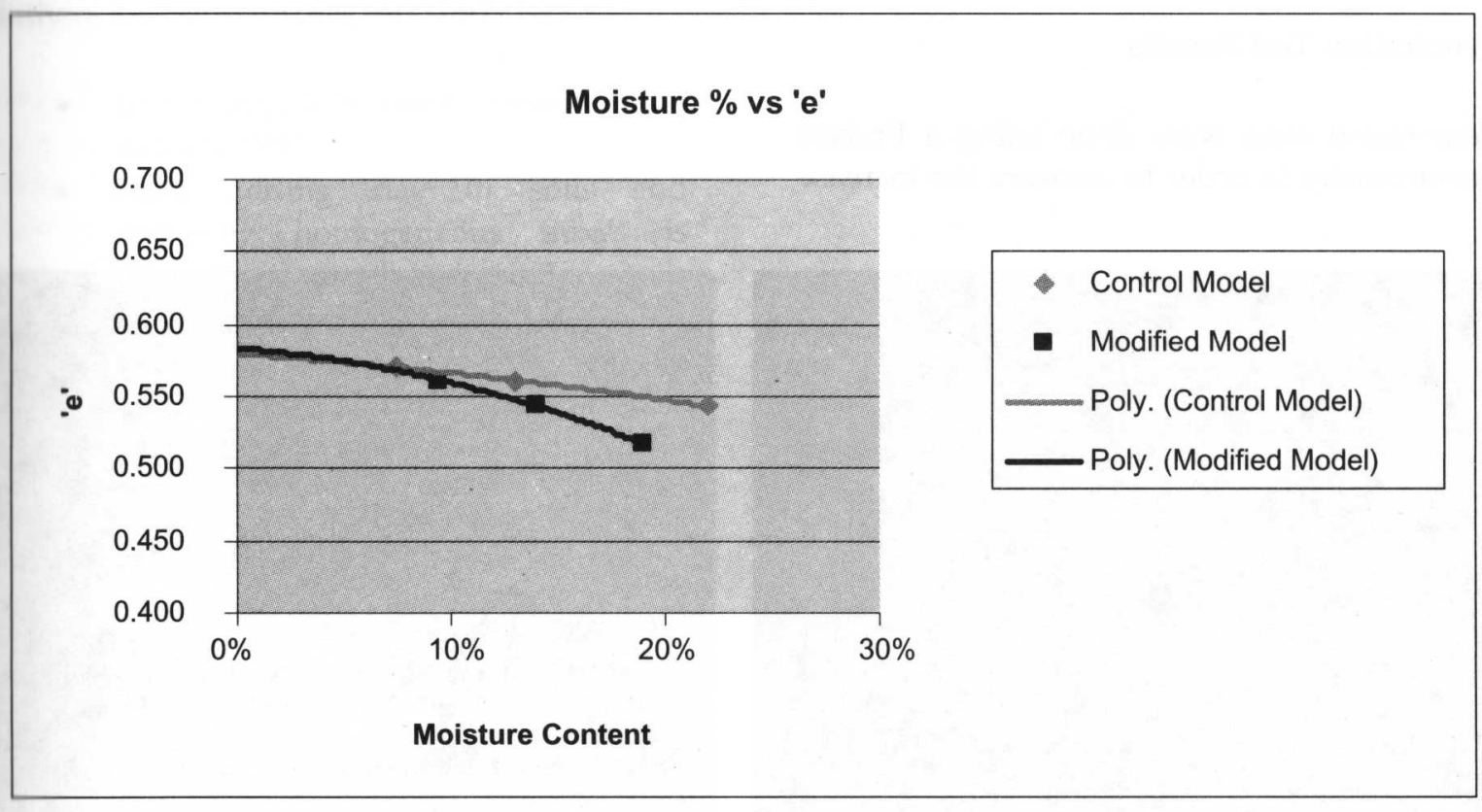

Figure 7: Moisture Content vs Coefficient of Restitution for the models 


\section{Friction Test Results}

The friction test showed that the coefficient of friction of the surface of the modified model increase more rapidly with the increase in moisture content than that of the control model. This is because the surface of the modified model got softer and more plastic with the addition of moisture due to the higher clay content and the different clay mineralogy. This behaviour is consistent with that observed in England where pitches got slower with the increase in clay content [8] due to the damp weather conditions. The ' $\mu$ ' value increased with the moisture content for both models. A summary of the results are given in the table below but their significance is questionable as the growth of grass on a pitch is likely considerably change these values.

Table 5: Friction test results

\begin{tabular}{|l|c|c|}
\hline & Moisture & $'{ }^{\prime}$ \\
\hline \multirow{3}{*}{$\begin{array}{l}\text { Control } \\
\text { Model }\end{array}$} & $7.5 \%$ & 0.51 \\
\cline { 2 - 3 } & $13 \%$ & 0.54 \\
\cline { 2 - 3 } & $22 \%$ & 0.62 \\
\hline \multirow{2}{*}{$\begin{array}{l}\text { Modified } \\
\text { Model }\end{array}$} & $10 \%$ & 0.51 \\
\cline { 2 - 3 } & $14 \%$ & 0.59 \\
\cline { 2 - 3 } & $19 \%$ & 0.65 \\
\hline
\end{tabular}

\section{Penetration Test Results}

Penetration tests were done using a Proctor Penetrometer in order to measure the increase

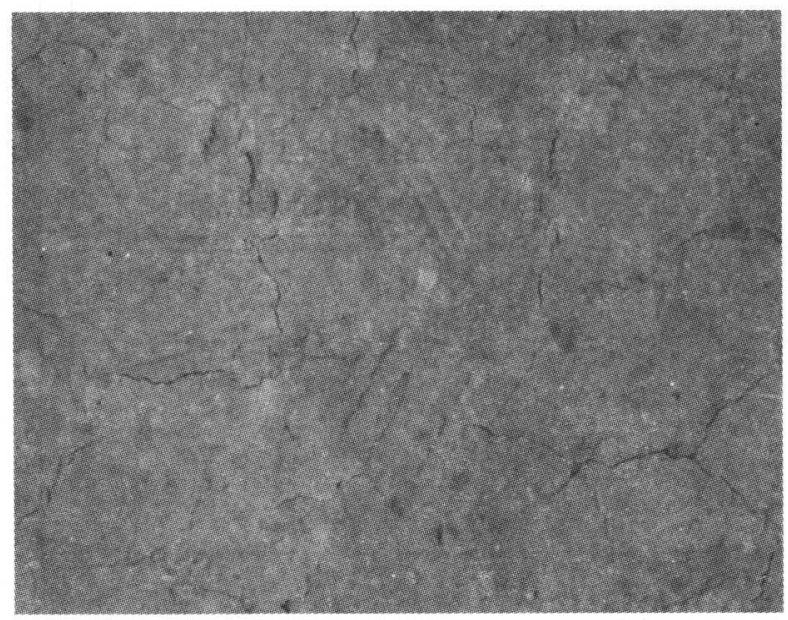

Modified Model in surface hardness as the moisture content decreased. But the results turned out to be of limited use as the surfaces of the models got too hard and exceeded the range of the instrument before useful trends could be identified.

\section{Crack Pattern}

The surfaces of both models were photographed as they dried out and then compared. As expected, the modified model showed more extensive cracking with larger crack widths. However, as the surface dried further it stayed stable and the cracks did not open up further or crumble. The control model on the other hand showed less cracking and the cracks were much finer.

\section{Deterioration}

While the bounce tests were being carried out, the modified model showed better resistance to deterioration. The control model tended to break up and crumble more readily than the modified model thus confirming that the improvement in the plasticity of the modified soil had improved its ability to resist crumbling.

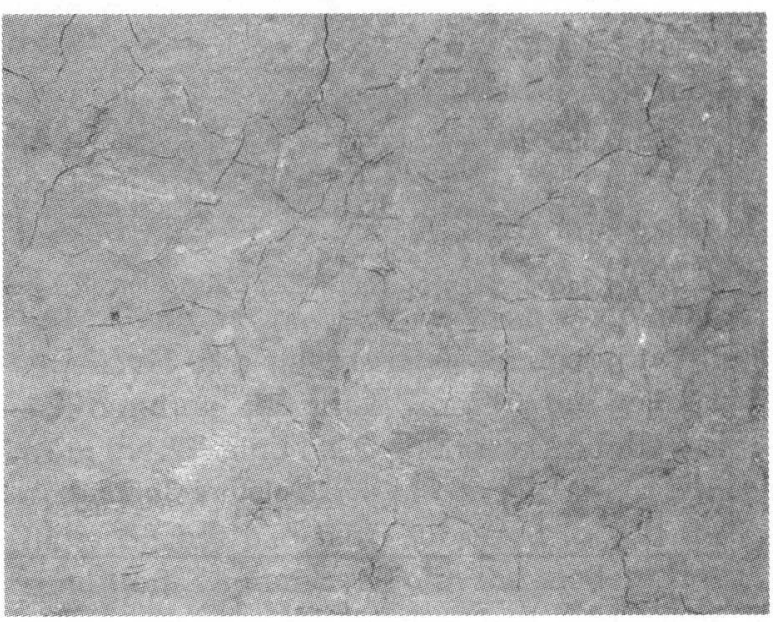

Control Model

Figure 8: Surfaces of the pitch models 
content

$o$ be of els got of the ald be

were then model larger dried lid not model ig and

ed out, istance ded to an the at the dified resist

\section{Conclusions}

From the tests carried out and their results, two conclusions can be drawn.

- The modified soil showed to have the potential to produce pitches with higher coefficients of restitution than was possible with the soil currently been used.

- The modified soil showed that it can produce surfaces which were better resistant to crumbling and powdering.

It can be argued that although the above results are true, the differences produced are not significant enough. The authors admit that the differences are indeed very small but more important than the absolute difference are the trends that have been identified.

It should not be forgotten that the clay content was only increase up to $50 \%$ whereas it can be increased to $80 \%$ as in the case of Perth, Australia. Plus, even though bentonite was added, the amount of kaolinite was still significant. So, if models are constructed with greater betonite content and less kaolinite in the soil even better results can be expected.

Further testing will be done to supplement what has been found through this study. The authors intend to further this study by,

- Increasing the bentonite content in the soil upto $80 \%$

- Since adding clay to soils and obtaining homogeneous mixes is difficult, naturally expansive soils found locally will be used in models to check how they perform

- Take in to account the effect of grass on the pitch performance

\section{References}

1. James D.M., Carre M.J. and Haake S.J. (2005) Predicting the playing character of cricket pitches Sports Engineering (2005) 8, 193-207

2. Daish C. (1972) The Physics of Ball Games, English Universities Press, London, UK

3. James D.M., Carre M.J. and Haake S.J. (2004) The playing performance of county cricket pitches. Sports Engineering, 7, 1-14
4. Carre M.J., Baker S.W., Newell A.J. and Haake S.J (1999) The dynamic behaviour of cricket balls during impact and variations due to grass and soil type

5. New Zealand Stadium Turf Institute Guide to Cricket Pitch Preparation

6. Herath J.W (1973) Industrial Clays of Sri Lanka

7. Carre M.J, Baker S.W., Newell A.J. and Haake S.J. (1999) The dynamic behavior of cricket balls during impact and viariations due to grass and soil type

8. www.golfandsportturf.com

\section{Acknowledgement}

The authors would like to convey their heartfelt gratitude to $\mathrm{Mr}$. Anurudda Polonnowita and Mr. Janaka Sampath of Sri Lanka Cricket for providing them with access to cricket grounds, soil samples for testing and preparing models, expertise on cricket pitch preparation and for their invaluable advice during the course of this study.

The staff of the Soil Mechanics Laboratory of the Department of Civil Engineering and Eng. L.P.S Rohitha of the Department of Earth Resources Engineering of the University of Moratuwa should also be thanked for their help and support. 